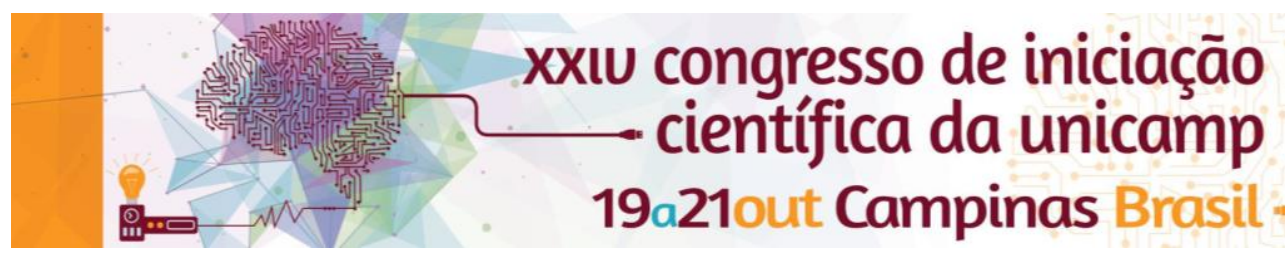

\title{
Resistência à Flexão de Vigas Metálicas Considerando a Posição das Cargas Transversais
}

\author{
Fernando Seto Takeguma Utikawa*, Leandro Palermo Júnior
}

\section{Resumo}

A análise de variação da resistência à flexão de vigas metálicas quando a resultante do carregamento transversal é deslocada do centro de gravidade da seção transversal. O efeito relaciona-se com a análise da Flambagem Lateral com Torção (FLT) que é sensível à posição da resultante do carregamento na seção transversal. A principal justificativa para o desenvolvimento do projeto é apresentar uma orientação para levar em conta este efeito considerando que a norma brasileira, dentre outras, não levam em conta este efeito de modo quantitativo, apesar de reconhecê-lo. Esta justificativa relaciona-se com o benefício à sociedade para o desenvolvimento desta proposta. $\mathrm{O}$ aluno que participa do projeto estudou a FLT o que melhorarou seu amadurecimento técnico no tema visto que o assunto é amplamente relacionado à aplicação das vigas metálicas nos projetos estruturais.

\section{Palavras-chave}

Flambagem Lateral com Torção, Flexo-Torção, Cargas Críticas

\section{Introdução}

As barras de seção delgada são intensamente usadas em estruturas metálicas por permitirem aplicações com ótima eficiência estrutural e mínimo custo. As verificações de instabilidade global formam a base do dimensionamento dessas barras, cujos fundamentos são relacionados à teoria de flexo-torção de Vlassov ${ }^{1}$. Tendo em conta estes aspectos, um código computacional foi desenvolvido pelo orientador para a análise estática, em regime elástico linear, de barras longas com seção transversal delgada a esqueleto aberto usando a teoria de flexo-torção com o emprego de elementos finitos unidimensionais. Assim, a determinação de cargas críticas de flexão, torção e flexo-torção, além do cálculo de deslocamentos com o efeito de não linearidade geométrica linearizado foram os produtos obtidos da análise. Observando-se, ainda, que o efeito da posição do ponto de aplicação dos carregamentos transversais em relação ao centro de gravidade (C.G.) da seção transversal pode ser levado em consideração na análise.

\section{Resultados e Discussão}

As vigas analisadas possuíam mesmo índice de esbeltez (200), e alturas de seção semelhantes, $250 \mathrm{~mm}$ para a seção $U$ formada a frio e $254 \mathrm{~mm}$ para as seções I e U laminadas. O momento crítico foi determinado para a normal valendo $5,10,15,30,60$ e $90 \%$ da normal crítica para a seção, os resultados obtidos apresentam-se na Figura 1.

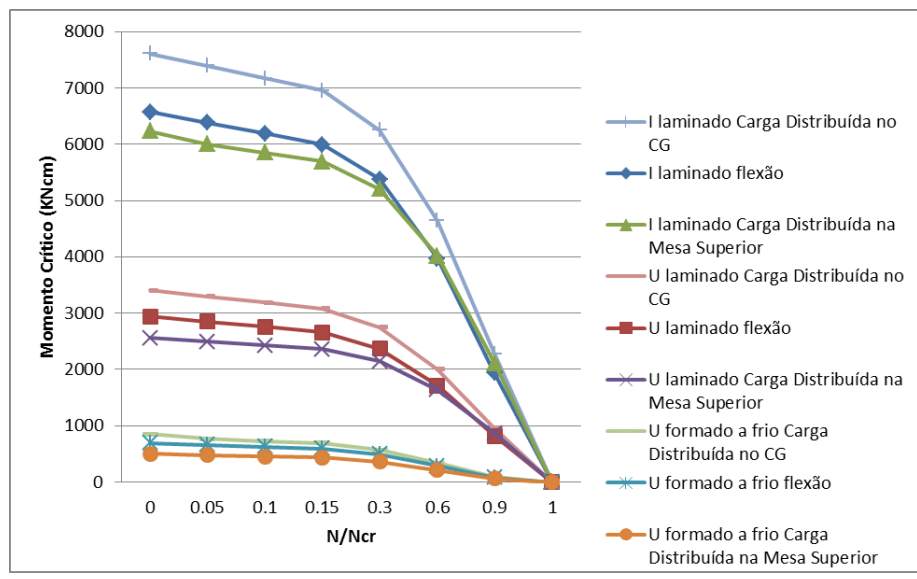

Figura 1. Valores de momento crítico para as vigas analisadas.

\section{Conclusões}

Na Figura 1 observa-se uma considerável redução do momento fletor resistente das vigas estudadas quando a carga se move do centro de gravidade para a mesa superior, portanto recomenda-se que em projetos com essas vigas onde há cargas consideráveis aplicadas na mesa superior, a carga não se aproxime da crítica.

\section{Agradecimentos}

Ao $\mathrm{PIBIC/CNPq/SAE/UNICAMP} \mathrm{pelo} \mathrm{incentivo} \mathrm{à}$ pesquisa e bolsa de estudos. E ao professor Leandro Palermo Júnior pela oportunidade e auxílio durante a pesquisa.

\footnotetext{
${ }^{1}$ Vlassov, B. Z., Pieces Longues en Voiles Minces, Editiones Eyrolles, Paris, France, 1962

${ }^{2}$ Palermo Júnior, L., Esforços de Flexão e Flexo- Torção em Teoria de Segunda Ordem, São Carlos, Escola de Engenharia de São Carlos - USP, 1985, 151 p. (Dissertação de Mestrado, Orientador : Munir Rachid)
} 